\title{
A combination of probiotics and whey proteins enhances anti-obesity effects of calcium and dairy products during nutritional energy restriction in aP2-agouti transgenic mice
}

\author{
Kazutoyo Yoda ${ }^{1 *}$, Xiaocum Sun ${ }^{2}$, Manabu Kawase ${ }^{1}$, Akira Kubota ${ }^{1}$, Kenji Miyazawa ${ }^{1}$, Gaku Harata $^{1}$, \\ Masataka Hosoda ${ }^{1}$, Masaru Hiramatsu ${ }^{1}$, Fang $\mathrm{He}^{1 *}$ and Michael B. Zemel ${ }^{2}$ \\ ${ }^{1}$ Technical Research Laboratory, Takanashi Milk Products Company Limited, Yokohama, Kanagawa 241-O023, Japan \\ ${ }^{2}$ Nutrition Institute, The University of Tennessee, Knoxville, TN 37996-1920, USA
}

(Submitted 14 November 2014 - Final revision received 5 February 2015 - Accepted 2 March 2015 - First published online 14 April 2015)

\section{Abstract}

Lactobacillus rhamnosus GG, Lactobacillus paracasei TMC0409, Streptococcus thermophilus TMC1543 and whey proteins were used to prepare fermented milk. For the experiment aP2-agouti transgenic mice were pre-treated with a high-sucrose/high-fat diet for 6 weeks to induce obesity. The obese mice were fed a diet containing $1.2 \% \mathrm{Ca}$ and either non-fat dried milk (NFDM) or probiotic-fermented milk (PFM) with nutritional energy restriction for 6 weeks. The animals were examined after the treatment for changes in body weight, fat pad weight, fatty acid synthase (FAS) activity, lypolysis, the expression levels of genes related to lipid metabolism, insulin sensitivity in adipocytes and skeletal muscle and the presence of biomarkers for oxidative and inflammatory stress in plasma. It was found that the PFM diet significantly reduced body weight, fat accumulation, and adipocyte FAS activity, and increased adipocyte lipolysis as compared with the effects of the NFDM diet $(P<0 \cdot 05)$. The adipose tissue gene expression of $11 \beta$-hydroxysteroid dehydrogenase 1 $(11 \beta-H S D 1)$ was significantly suppressed in mice that were fed PFM as compared with those that were fed NFDM $(P<0 \cdot 05)$. PFM caused a greater up-regulation of skeletal muscle PPAR $\alpha, P P A R \delta$, uncoupling protein 3 (UCP3) and GLUT4 expression and a significant decrease in the plasma concentration of insulin, malondialdehyde, TNF- $\alpha$, monocyte chemotactic protein- 1 and C-reactive protein as compared with the effects of NFDM $(P<0 \cdot 05)$. Fermentation of milk with selected probiotics and supplementation of milk with whey proteins may thus enhance anti-obesity effects of $\mathrm{Ca}$ and dairy products by the suppression of adipose tissue lipogenesis, activation of fat oxidation in skeletal muscle and reduction of oxidative and inflammatory stress.

Key words: Lactobacillus rhamnosus GG: Lactobacillus paracasei TMC0409: Streptococcus thermophilus TMC1543: Obesity: Nutritional energy restriction

A dramatic increase in obesity percentage is becoming not only a serious public health problem, but also a global scale economic problem. Obesity contributes to a high risk of CVD, type-2 diabetes, and hypertension. Moreover, emerging data show that obesity is associated with immune dysfunction and increased susceptibility to bacterial and viral infections ${ }^{(1)}$. Accordingly, the rise in medical costs associated with obesity will likely result in serious economic impact in many countries.

Diet plays an important role in the control of obesity without significant economic costs. Among the many dietary approaches for controlling obesity, nutritional energy restriction is effective for short-term body weight control and body fat loss. However, this approach carries a risk of relapse ${ }^{(2)}$.
An alternative approach, which produces a long-term effect, is the increased intake of $\mathrm{Ca}$ and dairy products ${ }^{(3)}$. In fact, many human observational studies and clinical trials have so far suggested an inverse relationship between intake of dietary $\mathrm{Ca}$ or dairy products and body fat ${ }^{(4-9)}$. The underlying theory is that dietary $\mathrm{Ca}$ down-regulates intracellular $\mathrm{Ca}^{2+}$ in adipocytes by reducing the level of parathyroid hormone and vitamin $\mathrm{D}\left(1,25(\mathrm{OH})_{2} \mathrm{D}\right)$, thereby modulating lipid metabolism and TAG accumulation in adipocytes ${ }^{(10-12)}$. In addition, dairy products act as an efficient source of dietary $\mathrm{Ca}$ as well as other bioactive substances such as angiotensin-converting enzyme inhibitors and branched-chain amino acids, which are mainly present in whey proteins. Thus, dairy consumption may increase the intake of dietary $\mathrm{Ca}$ and other active

Abbreviations: $11 \beta$-HSD1, 11 -hydroxysteroid dehydrogenase type I; MDA, malondialdehyde; NFDM, non-fat dried milk; PFM, probiotic-fermented milk.

*Corresponding authors: Dr F. He, fax +81 45364 2160, email ka-hou@takanashi-milk.co.jp; Dr K. Yoda, fax +81 453642160 , email k-yoda@takanashimilk.co.jp 
ingredients, thereby modulating energy metabolism, and attenuating the risk of obesity.

In the aforementioned studies, non-fat dried milk (NFDM) and/or normal yogurt were utilised as dairy products to examine the anti-obesity effects. A previous study showed that there was no remarkable difference in the anti-obesity effects of NFDM and normal yogurt ${ }^{(13)}$. A recent development is the addition of probiotics to fermented milk products, such as yogurt. Probiotics are defined as live microorganisms that, when administered in adequate amounts, confer a health benefit on the host ${ }^{(14)}$. There are a wide variety of health-promoting effects of probiotics, such as the prevention and/or treatment of diarrhoea, infectious diseases and allergic diseases, in a straindependent manner ${ }^{(15-18)}$. However, emerging data suggest that probiotics may also confer anti-obesity effects ${ }^{(19)}$. Given the fact that probiotic dairy products are commonly consumed, the anti-obesity effects of probiotic dairy products should be compared with those of normal dairy products.

The present study was designed to evaluate the influence of fermentation of milk with probiotics and supplementation of milk with whey proteins on the anti-obesity effects of dietary $\mathrm{Ca}$ and dairy products, using aP2-agouti transgenic mice as the test model. Mice of the aP2-agouti transgenic type are susceptible to diet-induced obesity, and exhibit a human pattern of expression of obesity-related genes ${ }^{(20)}$. These mice can be maintained at a normal weight on a standard AIN-93G $\operatorname{diet}^{(21)}$, but can characteristically develop mild to moderate obesity (25-40\% increase in adipose tissue mass), when fed high sucrose/fat diets for 6 to 12 weeks. In previous studies, aP2-agouti transgenic mice were commonly used to examine the short-term effects of Ca on obesity and oxidative and inflammatory stress ${ }^{(11-13)}$. Fermented milk supplemented with whey proteins was prepared using probiotic strains of Lactobacillus rhamnosus GG, Lactobacillus paracasei TMC0409 (TMC0409) and Streptococcus thermophilus TMC1543. These probiotic strains and whey proteins demonstrated considerable anti-obesity effects in previous studies ${ }^{(22-27)}$. The fermented milk product was tested for its anti-obesity effects, using the aP2-agouti murine model.

\section{Materials and methods}

\section{Fermented milk}

Fermented milk was supplemented with $1 \%$ whey protein concentrate 80 , and was fermented with probiotic strains of L. rhamnosus GG, L. paracasei TMC0409 and S. thermophilus TMC1543 (Takanashi Milk Products Company Limited). There were more than 10 million viable cells of each strain in $1 \mathrm{ml}$ of this product. After fermentation, probiotic-fermented milk (PFM) was lyophilised and stored at $-80^{\circ} \mathrm{C}$ until use. The lyophilised PFM was composed of $36 \cdot 8 \%$ protein, $0.8 \%$ fat and $49.3 \%$ carbohydrates, and contained $1469 \mathrm{~kJ}(351 \mathrm{kcal})$ of total energy/100 $\mathrm{g}$ of the powder.

\section{Mice and diets}

The present study was subdivided into two phases. Phase I was designed to induce weight gain and fat accretion, and
Phase II involved assessment of weight and fat loss as described below. The study utilised aP2-agouti transgenic mice from our colony. Three to four animals were housed together in polypropylene cages at a room temperature of $22 \pm 2^{\circ} \mathrm{C}$ and a $12 \mathrm{~h}$ light $-12 \mathrm{~h}$ dark cycle throughout the experimental period. The mice had free access to water. The present study was approved by the Institutional Care and Use Committee of The University of Tennessee.

\section{Phase I}

Male aP2-agouti transgenic mice of 6 weeks of age ( $n$ 45) were subjected to a basal (standard) diet for 6 weeks, consisting of a modified AIN-93G diet with suboptimal Ca intake $(0 \cdot 4 \%)$, a soy protein isolate as the protein source, sucrose as the sole carbohydrate source providing $62 \%$ of energy and fat supplying $24 \%$ of energy intake with lard serving as the supplemental fat source (Table 1). The mice were monitored for 6 weeks, during which food intake and spillage were measured daily, and body weight, fasting blood glucose and food consumption were assessed weekly.

\section{Phase II}

At the end of the Phase I duration of 6 weeks, five randomly selected representative mice were killed under isofluorane anaesthesia for baseline measurements. The remaining forty mice, weighing an average of 29.85 (SE 0.39) g, were randomised into four groups (ten per group). Each group followed one of four different diets: (1) the basal diet, ad libitum feeding; (2) the basal diet, restricted to $70 \%$ of the energy intake of the ad libitum group by using the pair-fed protocol; (3) the basal diet, with NFDM substituted for soy as a protein source, $\mathrm{Ca}$ increased to $1.2 \%$ and energy restricted to $70 \%$ of the energy intake of the ad libitum group and (4) the basal diet, with the PFM substituted for soy as the protein source, $\mathrm{Ca}$ increased to $1.2 \%$ and energy restricted to $70 \%$ of the energy intake of the ad libitum group. Macronutrient levels in these diets were adjusted to ensure that the protein, carbohydrate and fat contents were identical to those of the basal diet used as a control (Table 1). At the end of the 6 weeks, all the forty mice were killed under isofluorane anaesthesia. The fat pads, skeletal muscles (soleus and gastrocnemius) and livers were excised, weighed and used for further study as described below.

\section{Lipolysis assay}

Perirenal adipose tissue was immediately dissected, washed several times with Hank's Balanced Salt Solution, minced into small pieces and digested with $0 \cdot 8 \mathrm{~g} / 1$ type I collagenase in a shaking Water-bath at $37^{\circ} \mathrm{C}$ for $30 \mathrm{~min}$. Adipocytes were then filtered through sterile 500- $\mu$ m nylon mesh, and cultured in Dulbecco's Modified Eagle's Medium supplemented with $1 \%$ foetal bovine serum for $4 \mathrm{~h}$. Glycerol released into the culture medium was used to measure lipolysis, as described previously $^{(28)}$. Glycerol was measured using the 1-step enzymatic fluorometric method ${ }^{(29)}$. 
Table 1. Mouse diet composition

\begin{tabular}{|c|c|c|c|}
\hline & \multicolumn{3}{|c|}{ Diet } \\
\hline & $\begin{array}{c}\text { Basal } \\
(0.4 \% \mathrm{Ca})\end{array}$ & $\begin{array}{c}\text { NFDM } \\
(1.2 \% \mathrm{Ca})\end{array}$ & $\begin{array}{c}\text { PFM } \\
(1.2 \% \mathrm{Ca})\end{array}$ \\
\hline \multicolumn{4}{|l|}{ Ingredient (g) } \\
\hline Soya protein, HD90 & 160 & 0 & 0 \\
\hline Non-fat dried milk & 0 & 400 & 0 \\
\hline PFM & 0 & 0 & 390 \\
\hline DL-Met & 3 & 0 & 0 \\
\hline Sucrose & 637.9 & $429 \cdot 7$ & $445 \cdot 0$ \\
\hline Cellulose & 50 & 50 & 50 \\
\hline Soyabean oil & 100 & $97 \cdot 6$ & $96 \cdot 7$ \\
\hline Lard & 10 & 10 & 10 \\
\hline Mineral mix* & 7 & 7 & 7 \\
\hline Calcium carbonate & 10 & $17 \cdot 4$ & $7 \cdot 4$ \\
\hline $\begin{array}{l}\text { Potassium phosphate } \\
\text { monobasic }\end{array}$ & 8 & 8 & 8 \\
\hline Potassium citrate, $1 \mathrm{H}_{2} \mathrm{O}$ & 1.6 & 1.6 & 1.6 \\
\hline Vitamin mix V10037* & 10 & 10 & 10 \\
\hline Choline bitartrate & $2 \cdot 5$ & $2 \cdot 5$ & $2 \cdot 5$ \\
\hline$\alpha$-Butyl hydroquinone & 0.014 & $0 \cdot 014$ & 0.014 \\
\hline Total & $1000 \cdot 014$ & $1033 \cdot 814$ & $1028 \cdot 214$ \\
\hline \multicolumn{4}{|l|}{ Macronutrients (g) } \\
\hline Protein & $143 \cdot 8$ & $144 \cdot 8$ & 143.5 \\
\hline Carbohydrate & 637.9 & $637 \cdot 7$ & $637 \cdot 4$ \\
\hline Fat & 110 & 110 & 110 \\
\hline Fibre & 50 & 50 & 50 \\
\hline \multicolumn{4}{|l|}{ Macronutrients (\% of $\mathrm{g}$ ) } \\
\hline Protein & $14 \cdot 4$ & $14 \cdot 0$ & $14 \cdot 0$ \\
\hline Carbohydrate & $63 \cdot 8$ & $61 \cdot 7$ & $62 \cdot 0$ \\
\hline Fat & 11 & $10 \cdot 6$ & $10 \cdot 7$ \\
\hline Fibre & 5 & $4 \cdot 8$ & 4.9 \\
\hline \multicolumn{4}{|l|}{ Macronutrients (kcal) } \\
\hline Protein & 575 & 579 & 574 \\
\hline Carbohydrate & 2552 & 2551 & 2550 \\
\hline Fat & 990 & 990 & 990 \\
\hline Total & 4117 & 4120 & 4113 \\
\hline \multicolumn{4}{|l|}{ Macronutrients ( $\%$ of energy) } \\
\hline Protein & 14 & 14 & 14 \\
\hline Carbohydrate & 62 & 62 & 62 \\
\hline Fat & 24 & 24 & 24 \\
\hline Total & 100 & 100 & 100 \\
\hline
\end{tabular}

NFDM, non-fat dried milk; PFM, probiotic-fermented milk.

* Mineral and vitamin mix from AIN-93G diet ${ }^{(21)}$.

\section{Fatty acid synthase activity assay}

Fatty acid synthase (FAS) activity in crude cytosolic extracts of mouse adipose tissue was determined spectrophotometrically. Mouse abdominal fat pads were homogenised in a $250 \mathrm{~mm}-$ sucrose solution containing $1 \mathrm{~mm}$-EDTA, $1 \mathrm{~mm}$-dithiothreitol and $100 \mu \mathrm{m}$-phenylmethylsulfonyl fluoride ( $\mathrm{pH}$ 7.4). The homogenate was centrifuged at $18500 \mathrm{~g}$ for $1 \mathrm{~h}$, and the infranatant was used for measuring the oxidation rate of NADPH. The final FAS activity was normalised to DNA, which was measured using a CyQUANT cell proliferation assay kit, according to the manufacturer's instructions (Packard Instrument Company).

\section{Total RNA extraction}

A total cellular RNA isolation kit (Ambion, Inc.) was used to extract total RNA from murine abdominal adipose tissue and soleus muscle, according to the manufacturer's instruction.

\section{Quantitative real-time PCR}

Quantitative real-time PCR was performed to measure the expression levels of genes related to lipid metabolism and insulin sensitivity in adipocytes and skeletal muscle, as described previously ${ }^{(13,20,30)}$. Briefly, murine abdominal adipose tissue $F A S, 11 \beta$-hydroxysteroid dehydrogenase type I (11 $\beta$-HSD1), glucocorticoid receptor 1 (GR1) mRNA, and mouse soleus muscle PPAR $\alpha, P P A R \delta$, mitochondrial uncoupling protein 3 (UCP3) and GLUT type 4 (GLUT4) mRNA were quantified using an ABI 7300 Real-Time PCR System (Applied Biosystems) with a TaqMan 1000 Core Reagent Kit (Applied Biosystems). The primers and probe sets were ordered from Applied Biosystems TaqMan Assayson-Demand Gene Expression Collection of primers and probes, and used according to the manufacturer's instructions. Pooled total RNA from adipocytes was serially diluted in the
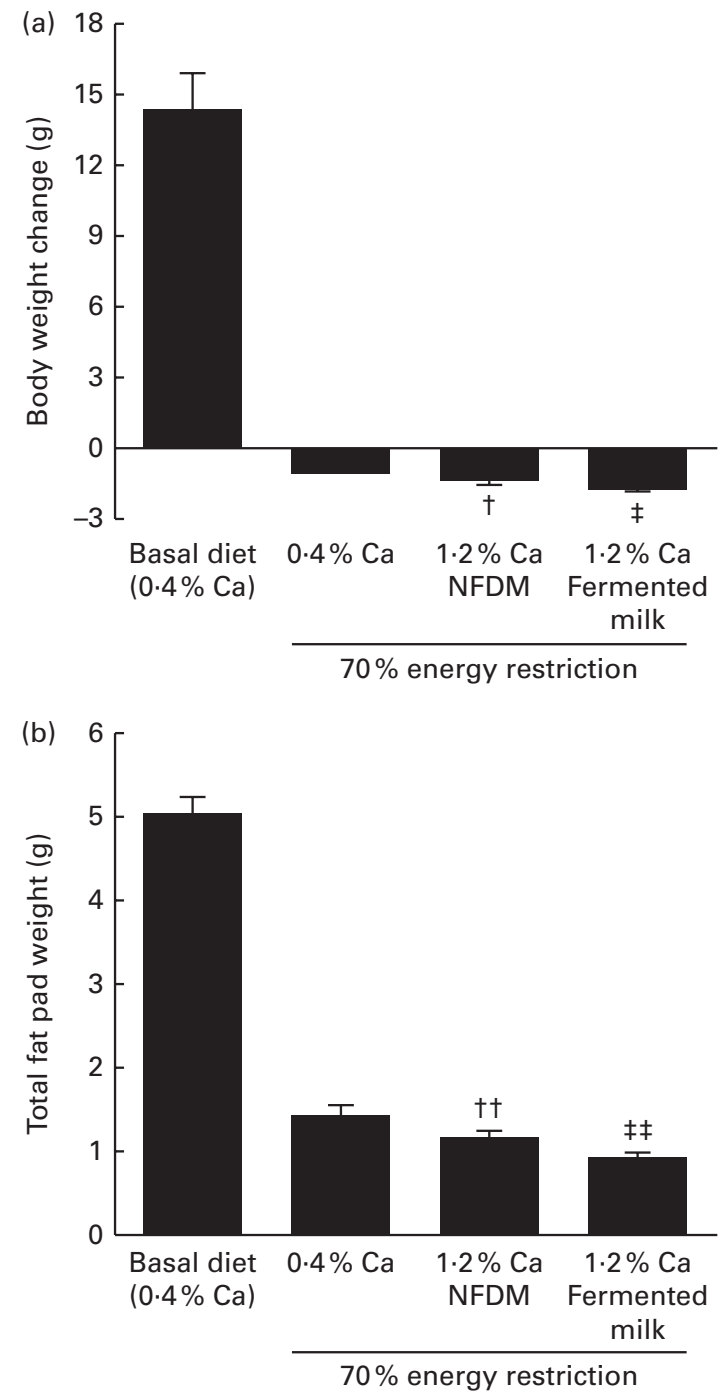

Fig. 1. Body weight change (a) and fat mass (b) in mice fed each diet after phase II. Values are means, with their standard errors represented by vertical bars $(n 10)$. Mean value was significantly different from that of the energyrestricted group fed the $0.4 \%$ calcium diet: $\dagger P<0.05$, $\dagger \uparrow P<0.01$. Mean value was significantly different from that of the energy-restricted group fed the $1.2 \%$ calcium non-fat dried milk (NFDM) diet: $\ddagger P<0.05$, $¥ P<0.01$. 

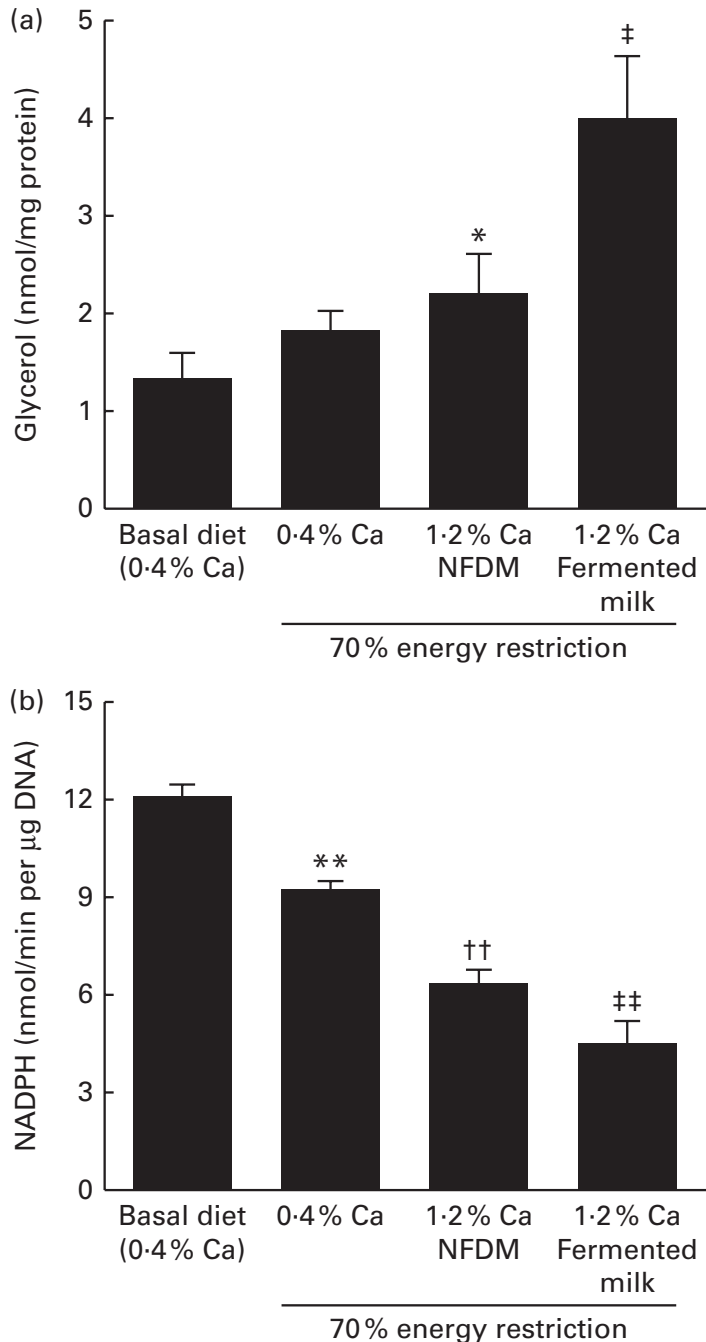

Fig. 2. Effect of each diet on adipose tissue lipolysis (a) and fatty acid synthase (FAS) activity (b). Values are means, with their standard errors represented by vertical bars $(n 10)$. Mean value was significantly different from that of the basal diet-fed group: ${ }^{*} P<0.05,{ }^{*} P<0.01$. †† Mean value was significantly different from that of the energy-restricted group fed the $0.4 \%$ calcium diet $(P<0.01)$. Mean value was significantly different from that of the energy-restricted group fed the $1.2 \%$ calcium non-fat dried milk (NFDM) diet: $\ddagger P<0.05$, $\neq \ddagger P<0.01$

range of $1 \cdot 6-25 \cdot 0 \mathrm{ng}$, and used to establish a standard curve; total RNA from unknown samples were also diluted in this range. Reactions of quantitative real-time PCR for standards and unknown samples were performed according to the instructions of the ABI 7300 Real-Time PCR System and the TaqMan 1000 Core Reagent Kit. The mRNA quantification data from each sample were normalised to $18 S$ levels.

\section{Measurement of blood chemistry markers}

Immediately after killing the mice, blood was collected via cardiac puncture and was centrifuged forthwith under refrigeration to obtain plasma for the measurement of insulin, malondialdehyde (MDA), TNF- $\alpha$, adiponectin, monocyte chemotactic protein-1 and C-reactive protein. Insulin and adiponectin levels were assessed using the Mouse Insulin and the Adiponectin ELISA Kits, respectively (Linco Research). MDA was assessed using the TBARS Assay Kit (ZeptoMetrix Corporation). The level of TNF- $\alpha$ was measured using the specific Mouse TiterZyme ELISA Kits from Assay Designs, Inc.. Plasma C-reactive protein levels were measured using the Mouse C-reactive protein ELISA Kit (Life Diagnostics, Inc.).

\section{Statistical analysis}

All data were expressed as means with their standard errors. The data were evaluated for statistical significance using one-way ANOVA, and the identification of a significantly different group depended upon separation in the leastsignificant-difference test, conducted with the SPSS software (SPSS, Inc.). Differences with $P<0.05$ were considered statistically significant.

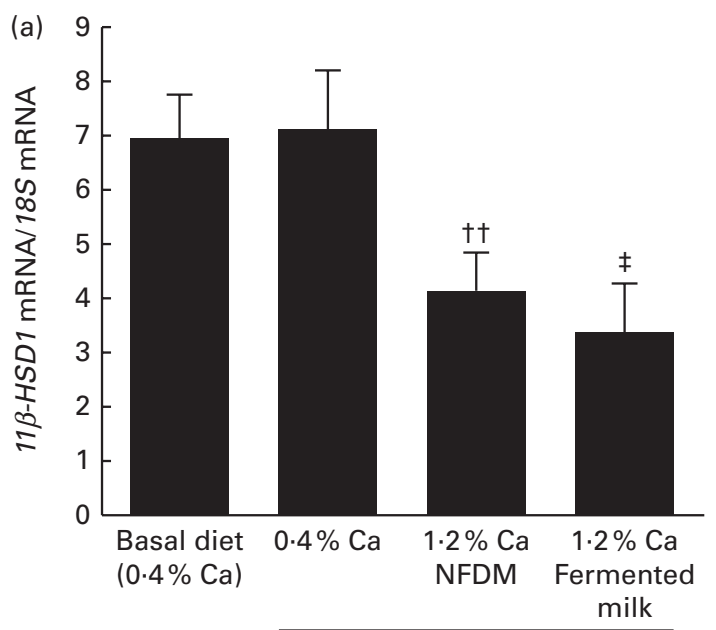

$70 \%$ energy restriction

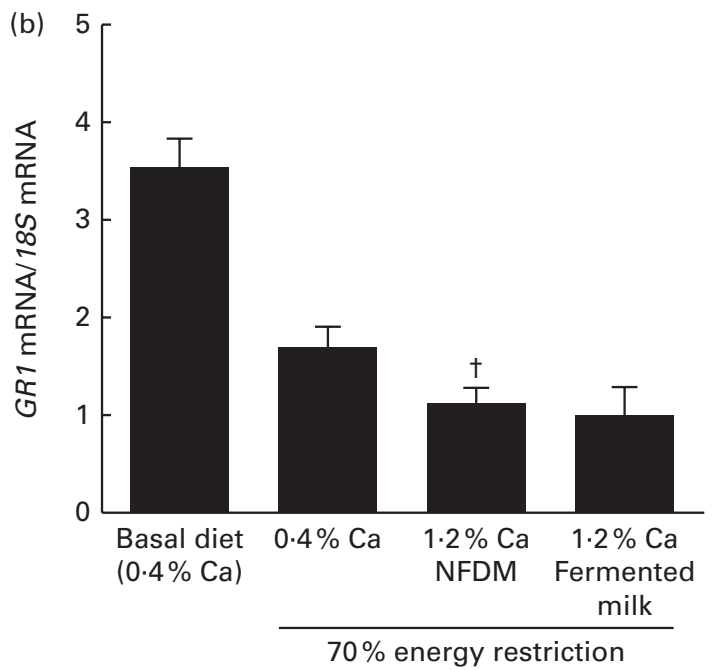

Fig. 3. Effect of each diet on mRNA expression of genes encoding $11 \beta-H S D 1$ (11ß-hydroxysteroid dehydrogenase type I) (a) and GR1 (glucocorticoid receptor 1) (b) in skeletal muscle of mice fed each diet. Values are means, with their standard errors represented by vertical bars $(n 10)$. Mean value was significantly different from that of the energy-restricted group fed the $0.4 \%$ calcium diet: $\dagger P<0.05, \dagger \dagger P<0.01$. $¥$ Mean value was significantly different from that of the energy-restricted group fed the $1.2 \%$ calcium nonfat dried milk (NFDM) diet $(P<0.05)$. 

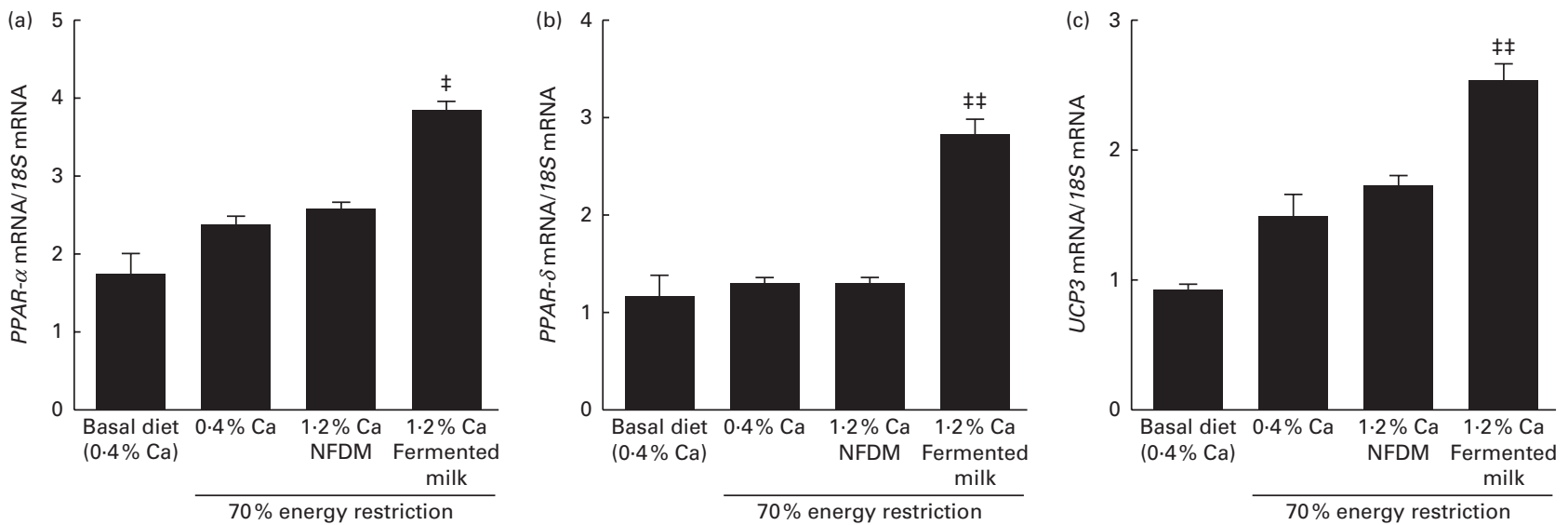

Fig. 4. mRNA expression of genes encoding PPAR- $\alpha$ (a), PPAR- $\delta$ (b) and UCP3 (uncoupling protein 3 ) (c) in skeletal muscle of mice fed each diet. Values are means, with their standard errors represented by vertical bars $(n 10)$. Mean value was significantly different from that of the energy-restricted group fed the $1.2 \%$ calcium non-fat dried milk (NFDM) diet: $\ddagger P<0.05$, $\ddagger \ddagger P<0.01$.

\section{Results}

Mice that were fed the basal (0.4\% Ca/high-sucrose/high-fat) diet exhibited a $49 \%$ weight gain during phase II, and energy restriction in those mice resulted in a reduction of $>3 \%$ of body weight (Fig. 1(a)). The mice that were fed the PFM diet showed the most significant weight reduction among the mice subjected to energy restriction; furthermore, the PFM diet resulted in the greatest suppression of fat accumulation (Fig. 1(b)).

Although energy restriction treatment did not influence lipolysis in the adipose tissue, mice that were fed a high-Ca/ dairy-based (NFDM or PFM) diet exhibited a significant increase in lipolysis compared with mice that were fed low-Ca diets. The PFM diet showed a greater increase in adipose tissue lipolysis than did the NFDM diet (Fig. 2(a)). FAS activity in the adipose tissue was significantly decreased by energy restriction, Ca supplementation and the change in protein sources (Fig. 2(b)). The expression of the FAS gene was also decreased by $\mathrm{Ca}$ supplementation and by replacement of protein sources (data not shown). Furthermore, the PFM diet suppressed expression of the FAS gene more than did the NFDM diet.

Dairy-based diets produced a significant decrease in the expression of a gene encoding $11 \beta-H S D 1$, an enzyme related to the glucocorticoid pathway and glucocorticoid receptor (Fig. 3). The PFM diet down-regulated the $11 \beta-H S D 1$ gene expression in adipose tissue to a greater degree than did the NFDM diet (Fig. 3(a)). Both diets triggered comparable effects on GR1 expression (Fig. 3(b)).

In the skeletal muscle, the expressions of genes encoding $P P A R \alpha, P P A R \delta$ and UCP3, which regulate fat oxidation, were significantly increased in mice that were fed the PFM diet as compared with other mice (Fig. 4).

To examine the indices of insulin sensitivity, expression of the gene encoding GLUT4 in skeletal muscle (Fig. 5(a)) and the circulating insulin level (Fig. 5(b)) were measured. In mice that were fed the PFM diet, GLUT4 expression was significantly increased compared with the other mice. The PFM diet also caused a greater decrease in the plasma insulin level than did the NFDM diet.

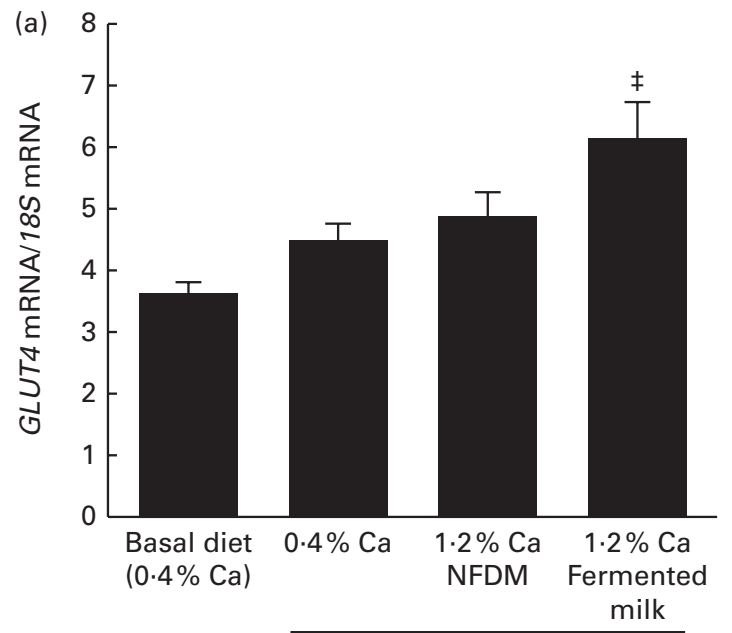

$70 \%$ energy restriction

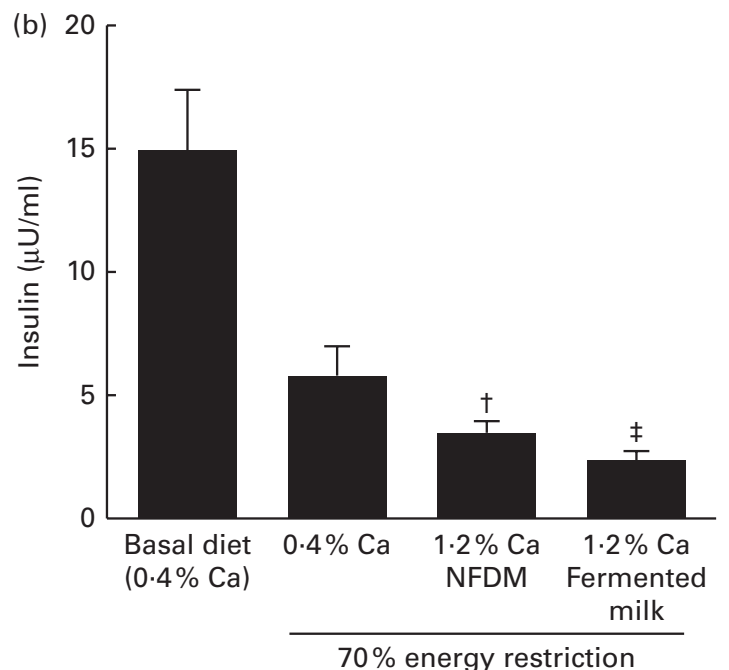

Fig. 5. Effect of each diet on GLUT4 expression (a) and plasma insulin level (b) in skeletal muscle. Values are means, with their standard errors represented by vertical bars $(n 10)$. † Mean value was significantly different from that of the energy-restricted group fed the $0.4 \%$ calcium diet $(P<0.05)$. $\ddagger$ Mean value was significantly different from that of the energy-restricted group fed the $1.2 \%$ calcium non-fat dried milk (NFDM) diet $(P<0.05)$. To convert insulin in $\mu \mathrm{U} / \mathrm{ml}$ to pmol/l, multiply by 6.945 . 

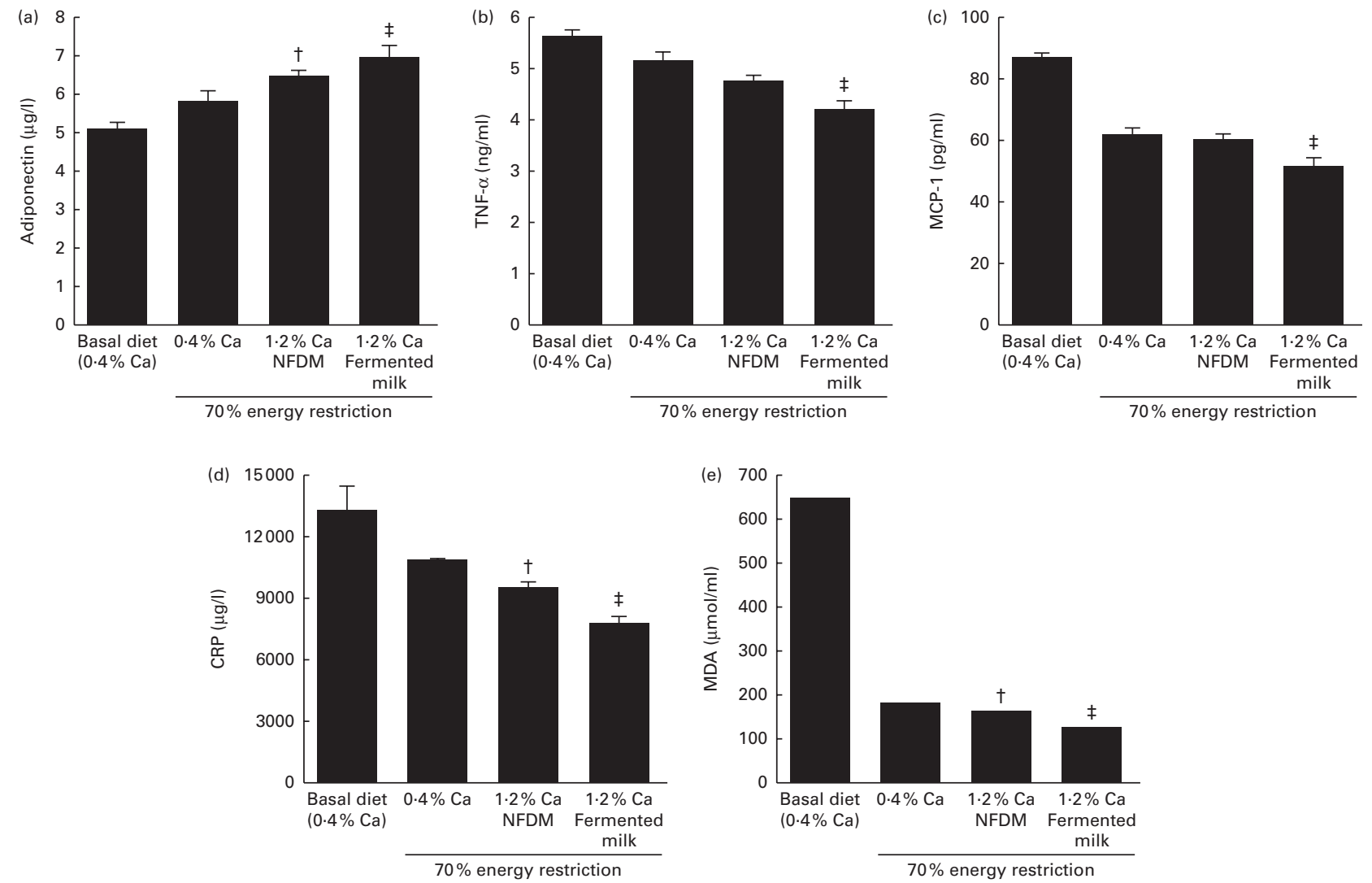

Fig. 6. Effects of each diet on indices of inflammatory and oxidative stress in plasma. The production levels of adiponectin (a), TNF- $\alpha$ (b), monocyte chemotactic protein-1 (MCP-1) (c), C-reactive protein (CRP) (d) and malondialdehyde (MDA) (e) in plasma. Values are means, with their standard errors represented by vertical bars $(n 10)$. † Mean value was significantly different from that of the energy-restricted group fed the $0.4 \%$ calcium diet $(P<0.05)$. $\ddagger$ Mean value was significantly different from that of the energy-restricted group fed the $1.2 \%$ calcium non-fat dried milk (NFDM) diet $(P<0.05)$.

The PFM diet significantly increased the plasma level of adiponectin (Fig. 6(a)), and down-regulated inflammatory cytokines TNF- $\alpha$, monocyte chemotactic protein- 1 and C-reactive protein (Fig. 6(b)-(d)). Plasma MDA, a marker of oxidative stress, was significantly decreased in mice subjected to energy restriction compared with mice that were fed the basal diet (Fig. 6(d)). The PFM diet caused a greater decrease of the plasma MDA level than did the other diets.

\section{Discussion}

The present study demonstrated that milk fermented by three selected probiotic strains and supplemented with whey proteins significantly augmented the anti-obesity effects of $\mathrm{Ca}$ and dairy products in energy-restricted aP2-agouti transgenic mice. The PFM diet reduced body weight and body fat, and modulated adipose tissue lipid metabolism, such as the promotion of lipolysis and the suppression of FAS activity, to a greater degree than did the NFDM diet. In contrast, energy restriction affected just the reduction of body weight and body fat, but not lipolysis and FAS gene expression (data not shown) in adipose tissue. Similar results were observed in a previous study ${ }^{(11)}$. Considering the fact that obesity is associated with abnormal lipid metabolism ${ }^{(31)}$, it is important to formulate methods of counteracting abnormal lipid metabolism, so as to intrinsically control obesity. The previous study additionally demonstrated that dietary Ca and NFDM played a key role in the modulation of lipid metabolism in adipose tissue under energy restriction ${ }^{(11)}$. Since both the PFM diet and the NFDM diet had the same composition of $\mathrm{Ca}$ in the present study, it is observed that fermentation of milk with probiotics and/or supplementation of milk with whey proteins, promote the modulatory effect of dietary Ca and dairy products on lipid metabolism.

To assess in clear terms the modulatory effect of the PFM diet on lipid metabolism, the adipocyte glucocorticoid pathway was analysed. $11 \beta-H S D 1$ is an enzyme that converts inactive cortisone to cortisol, the principal active glucocorticoid, resulting in activation of the glucocorticoid pathway. In adipose tissue, glucocorticoids promote the differentiation of preadipocytes into adipocytes, which could lead to increased body fat mass ${ }^{(32)}$. Moreover, the elevation of adipose $11 \beta$ HSD1 activity is observed in obese subjects ${ }^{(33)}$. In the present study, the PFM diet significantly suppressed the gene expression of $11 \beta-H S D 1$ compared with the NFDM diet. On the other hand, there was no difference between the two diets in the expression level of the gene encoding $G R$, which works downstream of $11 \beta$-HSD1 in the glucocorticoid pathway. The PFM diet may inhibit the activated glucocorticoid pathway in adipose tissue through the suppression of $11 \beta$-HSD1 gene expression, resulting in a greater reduction of body fat than that observed with the NFDM diet. 
The most impressive outcomes of the present study were that the PFM diet up-regulated the expression of genes related to fatty acid oxidation, such as PPAR and UCP3 and up-regulated glucose uptake via GLUT4 in skeletal muscle in contrast to the NFDM diet. Inefficient muscle fatty acid utilisation promotes fat storage above oxidation, leading to increased adipose tissue and TAG storage within skeletal muscle, thereby promoting obesity and insulin resistance ${ }^{(34)}$. In obese subjects, abnormality of GLUT4 expression inhibits the transport of plasma glucose into skeletal muscle cells, resulting in an increased plasma insulin level. In fact, the present study showed that the PFM diet decreased plasma insulin level significantly as compared with the NFM diet. Therefore, the PFM diet may increase energy consumption in skeletal muscle and enhance the anti-obesity effects of dietary $\mathrm{Ca}$ and dairy products.

Obesity is associated with chronic inflammation and oxidative stress ${ }^{(35,36)}$. Adipose tissue normally releases into circulation anti-inflammatory cytokines (which also regulate glucose levels and fatty acid breakdown) such as $\operatorname{adiponectin}^{(37)}$, and pro-inflammatory cytokines such as TNF- $\alpha$, and maintains the balance between these anti- and pro-inflammatory cytokines. Nonetheless, the enlarged adipocytes observed in obese subjects produce more of TNF- $\alpha$ and monocyte chemotactic protein-1, which migrate and infiltrate monocytes/macrophages ${ }^{(38)}$, leading to chronic inflammation and oxidative stress. The significant increase in plasma adiponectin levels in mice that were fed the PFM diet indicated that the PFM diet induced an anti-inflammatory response. This anti-inflammatory response was consistent with the up-regulation of the expression of genes related to fatty acid oxidation and glucose uptake in skeletal muscle. The PFM diet also markedly reduced plasma C-reactive protein and MDA, which are suitable markers for indicating the level of inflammation and oxidative stress, respectively. These outcomes were consistent with the significant reduction of plasma TNF- $\alpha$ and monocyte chemotactic protein- 1 observed in mice that were fed the PFM diet. Therefore, the results of the present study suggest that the PFM diet regulates the balance between anti-inflammatory and inflammatory response and suppresses oxidative stress in obese mice.

The present study did not assess the contribution in isolation of each of the probiotic strains and whey proteins to the above-mentioned effects of the PFM diet. For instance, L. rhamnosus GG, is known to increase the expression of genes related to fatty acid oxidation and glucose uptake in skeletal muscle, and reduce plasma insulin level in murine models ${ }^{(39,40)}$. Whey proteins, which are enriched in branched-chain amino acids, are, in addition, considered as potent up-regulators of fatty acid utilisation in skeletal muscle ${ }^{(30,41,42)}$. Therefore, further studies are needed to clarify precisely the contribution of each of these factors as a potent enhancer of the anti-obesity effects of dietary $\mathrm{Ca}$ and dairy products.

In summary, the present study demonstrated the new finding that fermentation of milk with selected probiotics and supplementation of milk with whey proteins may promote the anti-obesity effects of dietary $\mathrm{Ca}$ and dairy products during nutritional energy restriction in aP2-agouti mice; and this may be done via regulation of lipid and glucose metabolisms and via reduction of oxidative and inflammatory stress. Data from this study also provide the possibility of developing an effective strategy for the control of weight and obesity without high medical costs.

\section{Acknowledgements}

The authors would like to thank Enago (www.enago.jp) for the English language review.

This work was supported by Takanashi Milk Products Company Limited.

K. Y., M. K., A. K., K. M., G. H., M. Hosoda, M. Hiramatsu and F. H. are employees of Takanashi Milk Products Company Limited. X. S. and M. B. Z. have no competing interests. The authors have no conflicts of interest. The funding agency had no role in the design, conduct, findings or the writing of this research report.

M. B. Z., M. K., M. Hiramatsu, and F. H. designed this study. X. S. and M. B. Z. conducted the animal study. K. Y., M. K., A. K., K. M., G. H., M. Hosoda and F. H. provided technical support and prepared the fermented milk. K. Y., X. S., M. K., K. M., and F. H. analysed the data. K. Y. and F. H. wrote and revised the manuscript.

\section{References}

1. Huttunen R \& Syrjanen J (2013) Obesity and the risk and outcome of infection. Int J Obes (Lond) 37, 333-340.

2. Elfhag K \& Rossner S (2005) Who succeeds in maintaining weight loss? A conceptual review of factors associated with weight loss maintenance and weight regain. Obes Rev $\mathbf{6}$, $67-85$.

3. Zemel MB (2004) Role of calcium and dairy products in energy partitioning and weight management. Am J Clin Nutr 79, 907S-912S.

4. Lin YC, Lyle RM, McCabe LD, et al. (2000) Dairy calcium is related to changes in body composition during a two-year exercise intervention in young women. J Am Coll Nutr 19, $754-760$.

5. Lovejoy JC, Champagne CM, Smith SR, et al. (2001) Ethnic differences in dietary intakes, physical activity, and energy expenditure in middle-aged, premenopausal women: the Healthy Transitions Study. Am J Clin Nutr 74, 90-95.

6. Carruth BR \& Skinner JD (2001) The role of dietary calcium and other nutrients in moderating body fat in preschool children. Int J Obes Relat Metab Disord 25, 559-566.

7. Heaney RP, Davies KM \& Barger-Lux MJ (2002) Calcium and weight: clinical studies. J Am Coll Nutr 21, 152S-155S.

8. Zemel MB, Thompson W, Milstead A, et al. (2004) Calcium and dairy acceleration of weight and fat loss during energy restriction in obese adults. Obes Res 12, 582-590.

9. Zemel MB, Richards J, Milstead A, et al. (2005) Effects of calcium and dairy on body composition and weight loss in African-American adults. Obes Res 13, 1218-1225.

10. Zemel MB (2003) Role of dietary calcium and dairy products in modulating adiposity. Lipids 38, 139-146.

11. Shi H, Dirienzo D \& Zemel MB (2001) Effects of dietary calcium on adipocyte lipid metabolism and body weight regulation in energy-restricted aP2-agouti transgenic mice. FASEB J 15, 291-293. 
12. Shi H, Norman AW, Okamura WH, et al. (2001) 1 $\alpha, 25$-Dihydroxyvitamin $\mathrm{D}_{3}$ modulates human adipocyte metabolism via nongenomic action. FASEB J 15, 2751-2753.

13. Sun X \& Zemel MB (2004) Calcium and dairy products inhibit weight and fat regain during ad libitum consumption following energy restriction in Ap2-agouti transgenic mice. J Nutr 134, 3054-3060.

14. Hill C, Guarner F, Reid G, et al. (2014) Expert consensus document. The International Scientific Association for Probiotics and Prebiotics consensus statement on the scope and appropriate use of the term probiotic. Nat Rev Gastroenterol Hepatol 11, 506-514.

15. Szajewska H \& Mrukowicz JZ (2001) Probiotics in the treatment and prevention of acute infectious diarrhea in infants and children: a systematic review of published randomized, double-blind, placebo-controlled trials. I Pediatr Gastroenterol Nutr 33, Suppl. 2, S17-S25.

16. Kawase M, He F, Kubota A, et al. (2009) Effect of fermented milk prepared with two probiotic strains on Japanese cedar pollinosis in a double-blind placebo-controlled clinical study. Int I Food Microbiol 128, 429-434.

17. Kawase M, He F, Kubota A, et al. (2009) Clinical effects of cell preparation of Lactobacillus GG and L. gasseri TMC0356 on perennial allergic rhinitis: a double-blind placebo-controlled trial. Int J Probio Prebio 4, 241-248.

18. Yoda K, Miyazawa K, Harata G, et al. (2013) Immunobiotics and antiviral immunity. In Probiotics: Immunobiotics and Immunogenics, pp. 365-381 [H Kitazawa, J Villena and S Alvarez, editors]. Boca Raton, FL: CRC Press.

19. Mekkes MC, Weenen TC, Brummer RJ, et al. (2014) The development of probiotic treatment in obesity: a review. Benef Microbes 5, 19-28.

20. Bruckbauer A \& Zemel MB (2009) Dietary calcium and dairy modulation of oxidative stress and mortality in aP2-agout and wild-type mice. Nutrients 1, 50-70.

21. Reeves PG (1997) Components of the AIN-93 diets as improvements in the AIN-76A diet. J Nutr 127, 838S-841S

22. Tabuchi M, Tamura A, Yamada N, et al. (2003) Hypocholesterolemic effect of Lactobacillus GG in hypercholesterolemic rats. Milchwissenschaft 58, 246-249.

23. Honda K, Moto M, Uchida N, et al. (2012) Anti-diabetic effects of lactic acid bacteria in normal and type 2 diabetic mice. J Clin Biochem Nutr 51, 96-101.

24. Hashimoto H, Yamazaki K, He F, et al. (1998) Effect of lactic acid bacteria on serum cholesterol level in rats fed cholesterol diet. Anim Sci Technol 69, 702-707.

25. Kawase M, Hashimoto H, Hosoda M, et al. (2001) Serum cholesterol-lowering effect of fermented milk with Streptococcus thermophilus TMC1543. Anim Sci J 72, 54-62.

26. Kawase M, Hashimoto H, Hosoda M, et al. (2001) Effect of fermented milk with Streptococcus thermophilus TMC1543 on serum lipid levels induced by a high-cholesterol diet in adult subjects. Milchwissenschaft 56, 496-499.
27. Kawase M, Hashimoto H, Hosoda M, et al. (2000) Effect of administration of fermented milk containing whey protein concentrate to rats and healthy men on serum lipids and blood pressure. J Dairy Sci 83, 255-263.

28. Xue B, Moustaid N, Wilkison WO, et al. (1998) The agouti gene product inhibits lipolysis in human adipocytes via a $\mathrm{Ca}^{2+}$-dependent mechanism. FASEB J 12, 1391-1396.

29. Boobis LH \& Maughan RJ (1983) A simple one-step enzymatic fluorometric method for the determination of glycerol in 20 microliters of plasma. Clin Chim Acta 132, 173-179.

30. Sun X \& Zemel MB (2009) Leucine modulation of mitochondrial mass and oxygen consumption in skeletal muscle cells and adipocytes. Nutr Metab (Lond) 6, 26.

31. Hu F, Zhang Y \& Song Y (2013) Lipid metabolism, metabolic syndrome, and cancer. In Lipid Metabolism, pp. 185-210 [RV Baez, editor]. Rijeka, Croatia: Intech Open Access Publisher.

32. Wang M (2005) The role of glucocorticoid action in the pathophysiology of the metabolic syndrome. Nutr Metab (Lond) 2, 3 .

33. Rask E, Walker BR, Soderberg S, et al. (2002) Tissue-specific changes in peripheral cortisol metabolism in obese women: increased adipose $11 \beta$-hydroxysteroid dehydrogenase type 1 activity. J Clin Endocrinol Metab 87, 3330-3336.

34. Blaak EE (2004) Basic disturbances in skeletal muscle fatty acid metabolism in obesity and type 2 diabetes mellitus. Proc Nutr Soc 63, 323-330.

35. Fantuzzi G (2005) Adipose tissue, adipokines, and inflammation. I Allergy Clin Immunol 115, 911-919.

36. Furukawa S, Fujita T, Shimabukuro M, et al. (2004) Increased oxidative stress in obesity and its impact on metabolic syndrome. J Clin Invest 114, 1752-1761.

37. Jaziri R, Aubert R, Roussel R, et al. (2010) Association of ADIPOQ genetic variants and plasma adiponectin isoforms with the risk of incident renal events in type 2 diabetes. Nephrol Dial Transplant 25, 2231-2237.

38. Deshmane SL, Kremlev S, Amini S, et al. (2009) Monocyte chemoattractant protein-1 (MCP-1): an overview. J Interferon Cytokine Res 29, 313-326.

39. Kim SW, Park KY, Kim B, et al. (2013) Lactobacillus rhamnosus GG improves insulin sensitivity and reduces adiposity in high-fat diet-fed mice through enhancement of adiponectin production. Biochem Biophys Res Commun 431, 258-263.

40. Tabuchi M, Ozaki M, Tamura A, et al. (2003) Antidiabetic effect of Lactobacillus GG in streptozotocin-induced diabetic rats. Biosci Biotechnol Biochem 67, 1421-1424.

41. Sun X \& Zemel MB (2007) Leucine and calcium regulate fat metabolism and energy partitioning in murine adipocytes and muscle cells. Lipids $\mathbf{4 2}, 297-305$.

42. Arakawa M, Masaki T, Nishimura J, et al. (2011) The effects of branched-chain amino acid granules on the accumulation of tissue triglycerides and uncoupling proteins in dietinduced obese mice. Endocr J 58, 161-170. 